\title{
Does the Milk Income Loss Contract program improve the technical efficiency of US dairy farms?
}

\author{
H.-H. Chang* and A. K. Mishrat ${ }^{1}$ \\ *Department of Agricultural Economics, National Taiwan University, Taipei 106, Taiwan \\ †Department of Agricultural Economics and Agribusiness, Louisiana State University AgCenter and Louisiana State University, \\ Baton Rouge 70803
}

\section{ABSTRACT}

Due to volatility in the income of dairy farmers, the 2002 farm bill introduced the Milk Income Loss Contract (MILC) payments that were extended in the 2008 farm bill. It has been argued that MILC payments would help large dairy farms and squeeze out small dairy operations. This paper contributes to this policy issue by empirically assessing the effect of MILC payments on the technical efficiency of US dairy farms. Using a large-scale dairy farm survey containing information from 2005, we apply a data envelopment analysis method to estimate technical efficiency of the dairy farms. A Tobit regression model was estimated to examine the roles of human capital of the farm operator, different farming practices, farm sizes, and MILC payments on technical efficiency of the dairy farms. Results indicate that the effects of the MILC payments were heterogeneous among farms of different sizes. Significant effects of MILC payments were only evident among large farms. In contrast, no significant effects were found for medium and small farms.

Key words: milk production, milk income loss contract payments, technical efficiency, data envelopment analysis

\section{INTRODUCTION}

Dairy price supports have been a fixture of US dairy policy since 1949. Price supports are a market intervention program - the government offers to purchase nonperishable dairy products from manufacturers at a specified (intervention) price level. Some dairy farmer groups sought a permanent direct payment program for dairy farmers to be included in the 2002 farm bill as a means of supplementing dairy farm income when farm milk prices are low (Chite, 2007; Jesse et al., 2008). Before the emergency payments made each year on an ad hoc basis in fiscal years 1999 through 2001, dairy

Received November 17, 2010.

Accepted February 3, 2011.

${ }^{1}$ Corresponding author: amishra@agcenter.lsu.edu farmers were generally not recipients of direct government payments. However, some groups contended that farm milk prices had been volatile in recent years and that dairy farmers needed more income stability. The Milk Income Loss Contract (MILC) program was initially authorized in the 2002 farm bill and extended with changes in the 2008 farm bill. In the 2002 version of the farm bill, the MILC target price ( $\$ 16.94$ per cwt) is in reference to the class I milk price at Boston. All dairy producers are eligible for the difference between the target price and the actual Boston class I price in any month in which prices fall below the target price. This payment applies to all milk regardless of class use. However, MILC has an annual producer payment limit that is linked to production. This program includes a payment limit feature that limits the amount of a producer's annual milk sales eligible for MILC payments.

During the 2002 farm bill debate, large dairy farmers expressed concern that the MILC program caused excess milk production that in turn decreased farm milk market prices (Chite, 2007). They contended that the MILC program negatively affected their income because their annual production was well in excess of the 2.4 million pounds payment limit, and any production in excess of 2.4 million pounds received the market price and no federal payments (Chite, 2007; Jesse et al., 2008). Annual production of 2.4 million pounds is roughly equal to the annual production of a herd of approximately 120 to 130 dairy cows. However, under the provisions of the 2008 farm bill, the production limit per operation increases to 2.985 million pounds (about 145 cows) for each fiscal year from October 1, 2008, through August 31, 2012. The production limit reverts to the original limit of 2.4 million pounds per fiscal year in September 2012. Once this volume cap is met, producers are no longer eligible for this income assistance for the remaining months of the current fiscal year. The MILC program does allow each producer to select the month to initiate payments during the fiscal year (Chite, 2007; Jesse et al., 2008).

It has been argued that MILC payments would influence the production decisions of dairy farmers (e.g., 
Herndon et al., 2005). Herndon et al. (2005) indicate that MILC payments may be an additional factor that dairy farmers may account for in their production decisions. Further, Eberle et al. (2004) projected that MILC program would be best suited for 120-cow dairy farm operations. Their study may imply that the MILC program will be more beneficial to smaller producers compared with larger operations. Although studies have focused on MILC program, none of the available studies has examined the effect of MILC program payments on the production efficiency of dairy farmers. Furthermore, do these payments have a differential effect on production efficiency between small and large dairy farms? To bridge the knowledge gap, the objective of this study was to assess the effect of MILC payments on production efficiency. Moreover, we investigated whether the effects were different for dairy farms of differing sizes.

\section{MATERIALS AND METHODS}

\section{Data}

Data were extracted from the Dairy Production Practices and Costs and Returns Report (Agricultural Resource Management Survey phase II, commonly referred to as ARMS; USDA Economic Research Service, 2005). Observations were collected using a survey jointly administered by the National Agricultural Statistics Service and the Economic Research Service of the USDA for dairy production during calendar year 2005. The ARMS data include detailed financial information, such as farm income and expenses, as well as farm and operator characteristics. The specific survey was taken from targeted dairy operations in 24 states that account for more than $90 \%$ of national milk production and cover all major production areas, and it elicited detailed information about the production practices on the farm and costs of milk production. To reach the goal of our study, we first limited our sample to those farms that produced dairy products as the primary farm practice, and farms without any milk production in 2005 were excluded. After accounting for nonresponses and missing data, information on 1,593 farms were used for the analysis.

Drawing on previous studies of dairy production (e.g., Lawson et al., 2004; Balcombe et al., 2006; Tauer and Mishra, 2006; Kompas and Che, 2006; Abdulai and Tietje, 2007; Bravo-Ureta et al., 2007; D'Haese et al., 2009; Nehring et al., 2009; Cabrera et al., 2010), several variables representing the inputs and output of dairy production, socio-demographic characteristics of the farm operator, farm practice, and participation in the government programs were specified. Milk produc- tion in kilograms was defined as the production output, and 5 other production inputs were also specified. The variable $N_{-} C O W$ was defined as the number of adult cows in the herd; the variable CAPITAL was the capital expense reported by the dairy farm operator (US\$); the variable $S \_L A B O R$ was defined as the total farming hours of the operator and unpaid family labor, and VAR_COST included the total expenditures on agricultural chemicals, marketing containers, bedding and litter, medical supplies, fuel, electricity and utility, repairs/maintenance of machinery and buildings, custom work, renting of machinery, and fees paid for professional services (US\$). The variable FEED_PUR was defined as the total cost of purchased feedstuffs (US\$).

Some other variables were also specified to examine technical efficiency (TE). Human capital theory posits that production efficiency is affected by age and educational attainment of the farm operator (Huffman, 1981). We included age of the operator, $O P \_A G E$, and dummy variables $O P_{-} E D U 1$ and $O P_{-} E D U 2$ for those with less than high school and completed high school or higher education, respectively. Because off-farm employment may be associated with farm production or management, a dummy variable $O P \_O F F$ was also defined to indicate if the farm operator worked off the farm. Other independent variables reflecting the farm management of milk production were included. They were a dummy variable representing milking frequency, $M \_F R E Q$, equal to 1 for the farms with a milking frequency more than twice a day; computerized milking system, F_COMPUTER, a dummy variable equal to 1 for farms that used a computerized milking system; $F \_R E C O R D$, a dummy variable equal to 1 for farms that kept production records; M_AUTOMATIC, a dummy variable equal 1 for farms with milking units that have automatic takeoffs; a dummy variable equal to 1 , for each, for farms that used a nutritionist, $F_{-} N U$ TRITION, veterinarian, F_VETERIN; and whether the operation used pasture or cropland to graze dairy cattle, G_PASTURE. Table 1 presents descriptive statistics for all the variables.

\section{Statistical Methods}

Our empirical analysis contained 2 steps. In the first stage, a data envelopment analysis (DEA) model was used to estimate the TE of the dairy farms. In step 2 , based on the estimated TE, we estimated a Tobit regression model to examine the extent to which the MILC payments, the socioeconomic characteristics of the principal operator, and production practices of the dairy farms may be associated with the TE of the dairy farms. 
Table 1. Sample statistics ${ }^{1}$

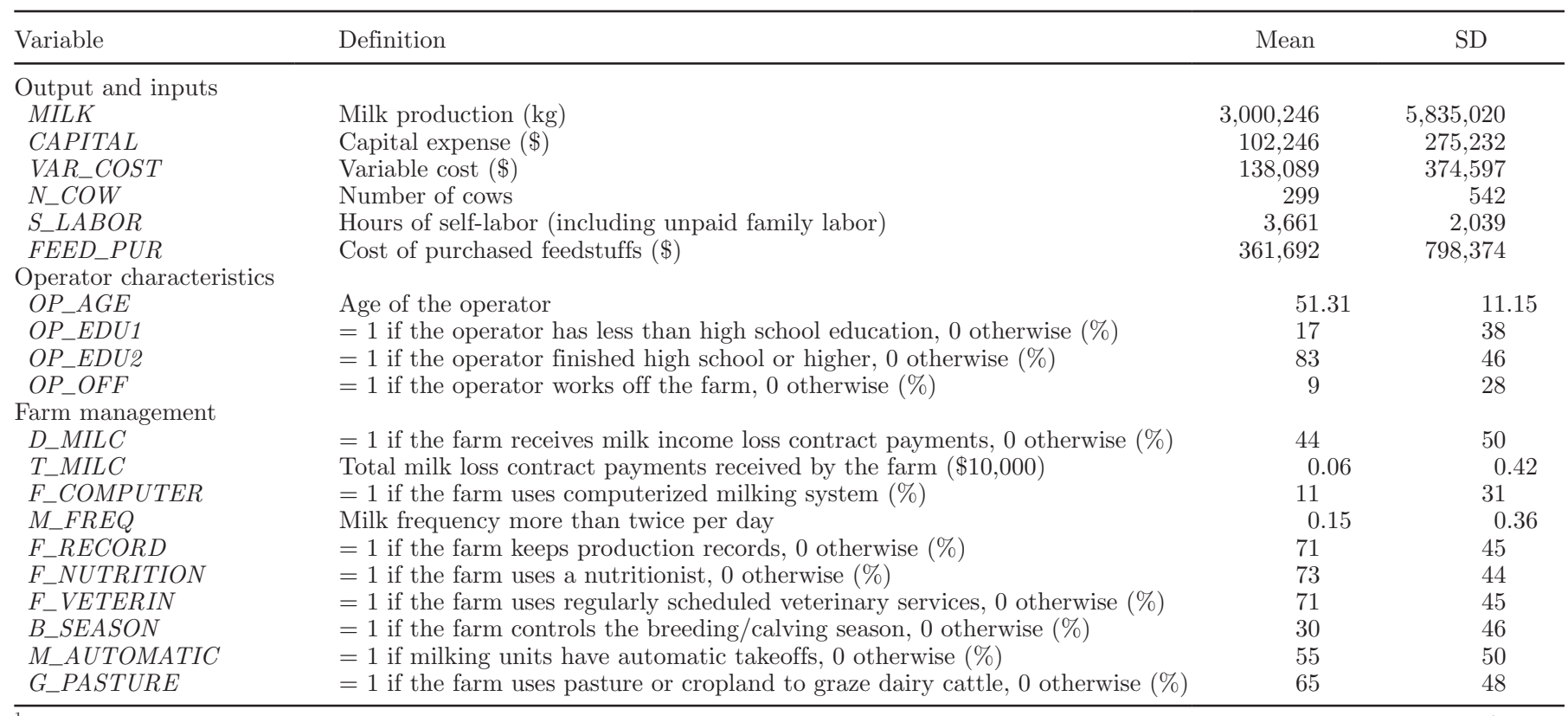

${ }^{1}$ Data included 1,593 dairy farm households. Source: 2005 Agricultural Resource Management Survey: Dairy costs and returns survey (USDA Economic Research Service, 2005).

\section{DEA Model}

The DEA model was originally proposed by Farrell (1957). The nonparametric strength of DEA has become increasingly popular in its applications in many different fields of study. The DEA method has also been applied to estimate the efficiency score of dairy farms (e.g., Bravo-Ureta et al., 2007; D'Haese et al., 2009). Compared with the other approach, stochastic production frontier model (or stochastic frontier analysis), which is also commonly used in productivity analysis, DEA analysis allows efficiency to be measured without having to specify the functional form of the production technology. In addition, efficiency measures are not significantly affected by small sample size in a DEA as long as the number of inputs is not high compared with the sample size (Thiam et al., 2001). The DEA method measures the relative efficiency by estimating an empirical production frontier, employing actual input and output data. The basic idea underlying DEA is to use linear programming methods to construct a piecewise surface over the production data for all decision-making units. In our study, each dairy farm was a decisionmaking unit. Measures of TE for each farm are then calculated relative to that surface (Coelli et al., 2005). This is accomplished by calculating a best performance measure for each farm, and comparing this measure to similarly calculated measures for all dairy farms.

Following Fare et al. (1994) and Coelli et al. (2005), assume that the $j$ th farm $(j=1, \ldots, j)$ uses $N$ inputs $\left(x_{j}=x_{1 j}, x_{2 j}, \ldots x_{n j}\right)$ to produce 1 output $\left(y_{j}\right)$. The input-oriented variable returns to scale DEA model of the $j$ th farm can be shown as

$$
\operatorname{Min}_{\lambda, \theta_{j}} \theta_{j}
$$

subject to

$$
\begin{gathered}
-y_{j}+\mathbf{Y} \boldsymbol{\lambda} \geq 0, \\
\theta x_{j}-\mathbf{X} \boldsymbol{\lambda} \geq 0, \\
\boldsymbol{\lambda} \geq 0, \\
\mathbf{I} 1^{\prime} \boldsymbol{\lambda}=1,
\end{gathered}
$$

where $\theta_{j}$ is a scalar of the measure of efficiency of the $j$ th farm; $\boldsymbol{\lambda}$ is a vector of constants; $\mathbf{I} 1$ is an $\mathbf{I} \times 1$ vector of $1 \mathrm{~s} ; \mathbf{Y}$ is a $J \times 1$ vector of output; and $\mathbf{X}$ is an $N \times J$ matrix of inputs. The TE for all farms could be obtained by solving the linear programming problem. In this envelopment form, the linear programming problem has a convenient interpretation in terms of TE. For the jth farm, in turn, the problem seeks to contract its input vector $x_{j}$ as much as possible while remaining in the feasible input set - the inner boundary of which is a piecewise linear isoquant (e.g., all input combinations that produce an equal output) that is 
determined by the observed data from all firms in the sample. The value $\theta_{j}$ then measures the TE for the $j$ th farm. Thus, a value of $\theta_{j}=1$ means that the farm is considered to be technically efficient, whereas a value $\theta_{j}<1$ means a farm is inefficient. For example, a value of $\theta_{j}=0.7$ means that a farm could reduce its input use by $30 \%$ and produce the same output.

The constraints [2], [3], and [4] ensure that the projected point cannot lie outside the data points. It should be noted that constraint [5] is a convexity constraint that results in the model being specified as a variable return to scale (VRS) model (Coelli et al., 2005). In contrast, without the convexity constraint, equations [1] to [4] are constraints that define a constant return to scale (CRS) model. In the CRS model, it is assumed that farms are operating at their optimal scale, whereas under VRS, the scale explains part of the inefficiency. In this study, we estimated both the CRS and VRS DEA models for technical efficiency.

\section{Estimating the TE Equation}

The second-stage analysis is to examine how MILC payments, socio-demographic characteristics of the farm operator, and farm practices may affect TE. Because the estimated maximum efficiency score of the dairy farms is set to 1 and some of the dairy farms have efficiency scores of 1, to account for the upper-limited problem, a Tobit model is specified for the TE equation (Greene, 2008). If we assume that $T E_{j}$ is the estimated TE score of the $j$ th farm, $M I L C_{j}$ is the MILC payments received from the government, and vector $\mathbf{X}_{j}$ represents the other exogenous determinants of the efficiency, the TE equation can be specified as follows:

$$
\begin{gathered}
T E_{j}^{*}=\alpha+\beta \mathbf{X}_{j}+\gamma M I L C_{j}+\varepsilon_{j}, \\
T E_{j}^{*}=T E_{j} \text { if } T E_{j}^{*}<1 \text { and } T E_{j}^{*}=1 \text { if } T E_{j}^{*}>1,
\end{gathered}
$$

where $T E_{j}^{*}$ is the latent variable for $\mathrm{TE}$, and $\varepsilon_{j}$ is a random error that is assumed to follow a normal distribution with zero mean and variance $\sigma^{2}$. The consistent parameters $(\alpha, \beta, \gamma, \sigma)$ can be estimated using the maximum likelihood estimation method based on the following log-likelihood function, L, (Greene, 2008):

$$
\begin{aligned}
\ln L & =\sum_{T E_{j}=1} \ln \Phi\left(\frac{-\alpha-\beta \mathbf{X}_{j}-\gamma M I L C_{j}}{\sigma}\right) \\
& +\sum_{T E_{j}<1} \ln \frac{1}{\sigma} \phi\left(\frac{T E_{j}-\alpha-\beta \mathbf{X}_{j}-\gamma M I L C_{j}}{\sigma}\right),
\end{aligned}
$$

where $\phi(),. \Phi($.$) are the probability density function$ and cumulative density function of the normal distribution, respectively.

It is of note that the parameters of the Tobit model present only the qualitative relationship between the exogenous variables and TE. The effect of the exogenous determinants on TE can be better understood by calculating the marginal effects that measure an additional change in the exogenous variables on the estimated efficiency score (Greene, 2008). Therefore, we report the results of the marginal effects in the empirical section. In addition, because the TE score estimated by the DEA model is used as the dependent variable, the standard errors of the estimation results are calculated based on the bootstrap method with 500 replications.

\section{RESULTS AND DISCUSSION}

The empirical results are presented in 2 parts. The first part presents the distributions of the estimated efficiency score. Estimations of the VRS and CRS models are presented (Table 2). Given the estimated TE score of the VRS model, Table 3 presents the estimations of the TE equation.

\section{Estimated TE}

Table 2 shows that the mean level of the TE score in the sample was 0.58 for VRS with standard deviation of 0.18. Similar conclusions can be drawn for CRS model (Table 2). The sample distribution of the TE of the VRS model is also depicted in Figure 1. Regarding the distribution of TE scores for VRS and CRS cases, results show that under the VRS model, approximately $18 \%$ of the dairy farms achieved TE levels of 0.75 or higher (Table 2). On the other hand, under the CRS model, $17 \%$ of the dairy farms achieved TE levels of 0.75 or higher. To examine the effects of the MILC program on TE of dairy farms, we also reported the sample statistics of the estimated TE for farms with and without MILC payments. Results show that in both cases (VRS and CRS), the mean TE scores were slightly higher (0.59) for dairy farms that received MILC payments than for their counterparts (0.58).

\section{Determinants of TE}

As discussed above, the sample distributions of the VRS and CRS models are quantitatively similar. Therefore, to save space and for ease of interpretation, we only present the TE scores estimated by the VRS model in Table 3 . In addition to the full sample, the efficiency equations are also estimated on a subsample 
Table 2. Sample distribution of the estimated technical efficiency $(\mathrm{TE})^{1}$

\begin{tabular}{|c|c|c|c|c|}
\hline \multirow[b]{2}{*}{ Item } & \multicolumn{4}{|c|}{ All samples } \\
\hline & \multicolumn{2}{|c|}{$\begin{array}{l}\text { VRS } \\
\text { model }\end{array}$} & \multicolumn{2}{|c|}{$\begin{array}{c}\text { CRS } \\
\text { model }\end{array}$} \\
\hline Mean & \multicolumn{2}{|c|}{0.583} & \multicolumn{2}{|c|}{0.577} \\
\hline $\mathrm{SD}$ & \multicolumn{2}{|c|}{0.181} & \multicolumn{2}{|c|}{0.180} \\
\hline TE interval & $\mathrm{n}$ & $\%$ & $\mathrm{n}$ & $\%$ \\
\hline 0 to 0.24 & 36 & 2 & 36 & 2 \\
\hline 0.25 to 0.49 & 516 & 32 & 531 & 33 \\
\hline 0.50 to 0.74 & 752 & 47 & 751 & 47 \\
\hline \multirow[t]{4}{*}{0.75 to 1} & 289 & 18 & 275 & 17 \\
\hline & \multicolumn{4}{|c|}{ Subsample } \\
\hline & \multicolumn{2}{|c|}{ With MILC $^{2}$ payments } & \multicolumn{2}{|c|}{ Without MILC payments } \\
\hline & \multicolumn{2}{|c|}{ Sample 696} & \multicolumn{2}{|c|}{ Sample 897} \\
\hline Model & VRS & CRS & VRS & CRS \\
\hline Mean & 0.593 & 0.589 & 0.579 & 0.574 \\
\hline SD & 0.190 & 0.189 & 0.169 & 0.168 \\
\hline
\end{tabular}

${ }^{1} \mathrm{VRS}$ is the variable return to scale model; CRS is the constant return to scale model.

${ }^{2} \mathrm{MILC}=$ milk income loss contract.

defined by farm size. In doing so, we were able to examine the differential effects of the exogenous variables on efficiency among dairy farms of different sizes.

We begin our discussion of the results in Table 3 by looking at the effect of the MILC payments on TE. Results showed that MILC payment was positively associated with the TE score of the dairy farms; however, statistically significant effects were found only for the large farms. Among the large dairy farms, an additional $\$ 10,000$ in MILC payments increased the TE score by
0.02 points. This result may reflect the possibility that MILC payments help the large dairy farms to increase their output/farm size and eventually contribute to better production efficiency. The MILC program may have indirectly benefited large dairy farms and proved to be counterproductive for small and medium-sized farms.

The socio-demographic characteristics of the farm operators and different farm management practices were also significantly associated with production ef-

Table 3. Estimated marginal effects (Mar. Eff.) of the technical efficiency equation ${ }^{1}$

\begin{tabular}{|c|c|c|c|c|c|c|c|c|}
\hline \multirow[b]{2}{*}{ Variable $^{2}$} & \multicolumn{2}{|c|}{ All samples } & \multicolumn{2}{|c|}{$\begin{array}{l}\text { Large farms } \\
(>300 \text { cows })\end{array}$} & \multicolumn{2}{|c|}{$\begin{array}{l}\text { Medium farms } \\
(100-299 \text { cows })\end{array}$} & \multicolumn{2}{|c|}{$\begin{array}{l}\text { Small farms } \\
(<100 \text { cows })\end{array}$} \\
\hline & Mar. Eff. & SE & Mar. Eff. & SE & Mar. Eff. & $\mathrm{SE}$ & Mar. Eff. & SE \\
\hline F_COMPUTER & $0.027 *$ & 0.014 & 0.007 & 0.017 & 0.035 & 0.026 & 0.046 & 0.047 \\
\hline$O P \_O F F$ & $-0.045^{* * *}$ & 0.015 & 0.037 & 0.035 & $-0.095^{* * *}$ & 0.033 & $-0.043^{* *}$ & 0.019 \\
\hline$O P \_A G E$ & 0.000 & 0.000 & 0.000 & 0.001 & 0.000 & 0.001 & $0.001^{*}$ & 0.001 \\
\hline$F \_R E C O R D$ & 0.004 & 0.010 & 0.025 & 0.027 & -0.004 & 0.018 & -0.009 & 0.014 \\
\hline F_NUTRITION & $0.027 * *$ & 0.011 & -0.019 & 0.029 & -0.004 & 0.021 & $0.037^{* *}$ & 0.015 \\
\hline F_VETERIN & $0.030^{* * *}$ & 0.011 & $0.055^{* *}$ & 0.027 & $0.054^{* * *}$ & 0.019 & 0.010 & 0.014 \\
\hline B_SEASON & -0.003 & 0.009 & -0.010 & 0.017 & -0.009 & 0.015 & 0.004 & 0.014 \\
\hline$M_{-}$AUTOMATIC & $0.047^{* * *}$ & 0.010 & $0.043^{*}$ & 0.022 & 0.018 & 0.017 & $0.026^{*}$ & 0.016 \\
\hline G_PASTURE & $-0.055^{* * *}$ & 0.010 & $-0.053^{* * *}$ & 0.016 & -0.023 & 0.014 & $-0.058^{* * *}$ & 0.018 \\
\hline$\sigma$ & $0.165^{* * *}$ & 0.003 & $0.154^{* * *}$ & 0.006 & $0.143^{* * *}$ & 0.005 & $0.175^{* * *}$ & 0.005 \\
\hline
\end{tabular}

${ }^{1}$ Marginal effects were calculated at the sample mean; the dependent variable is the estimated technical efficiency score from the variable return to scale (VRS) model. The Tobit model with upper limitation was used for estimation.

${ }^{2}$ See Table 1 for description of variables.

***, **, * indicate significant at 1, 5, and $10 \%$ level, respectively. 


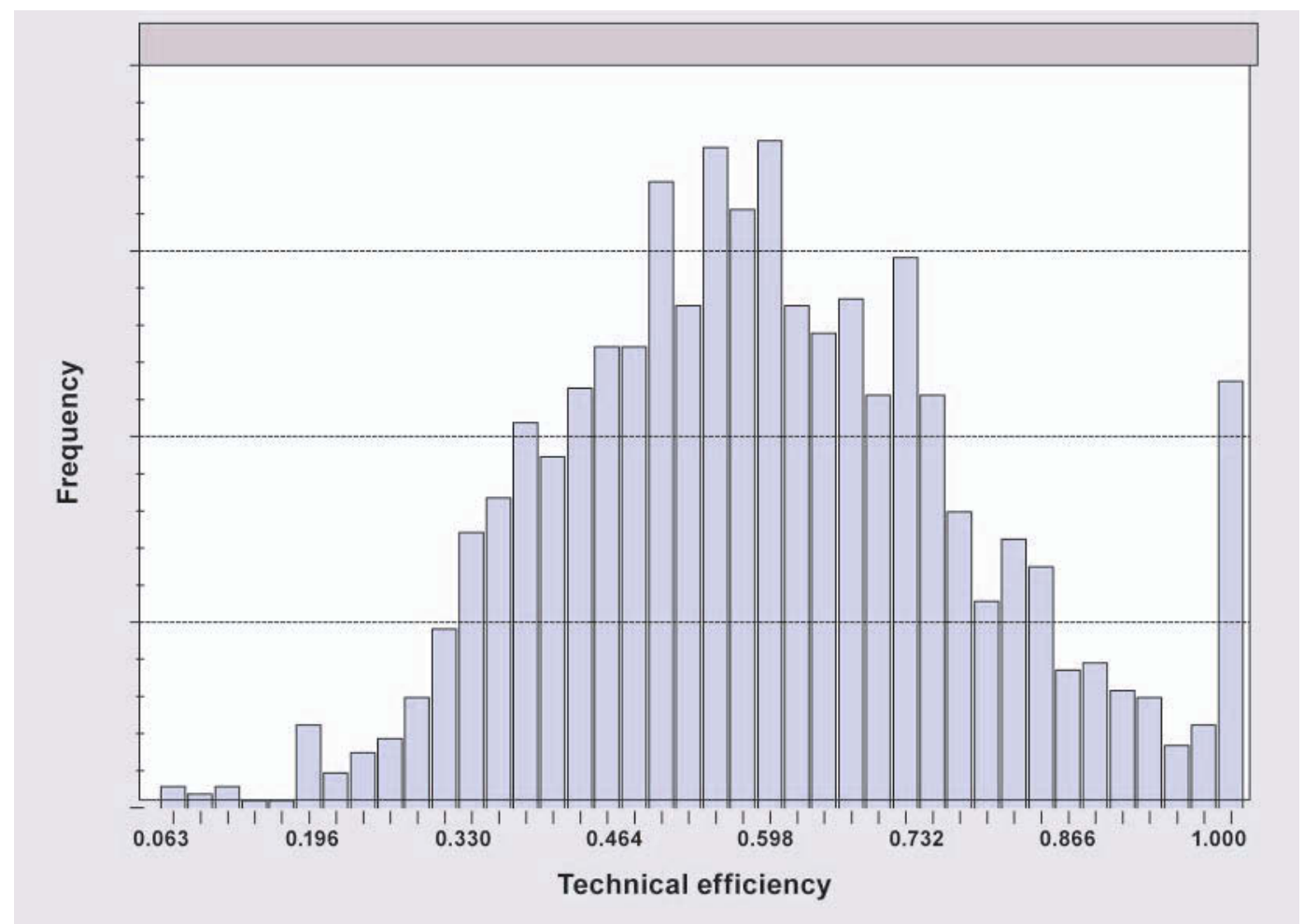
PDF.

Figure 1. Sample distribution of the technical efficiency of the variable return to scale (VRS) model. Color version available in the online

ficiency. Results in Table 3 suggest that, compared with the farm operators who did not finish high school (the variable $O P_{-} E D U 1$ ), dairy farm operators with at least a high school diploma had a higher TE score (0.02 points, on average). The positive effect of education on efficiency is more pronounced for small farms (0.03). This is consistent with the fact that education increases the productivity of labor and capital. On the other hand, off-farm income had a negative effect on TE. Results of the full-sample model indicated that dairy farm operators who reported off-farm income had lower efficiency scores, by 0.05 point, and the negative effect was more pronounced among the medium-sized dairy farms (0.10). Similarly, operators of small dairy farms who work off the farm had lower TE scores (0.04). This result is consistent with the finding in the literature that operators working off the farm spend less time on the farm (e.g., Mishra et al., 2002). Consequently, the production decisions will be based on less economic information, which tends to reduce efficiency.

In accordance with the findings of Cabrera et al. (2010) for Wisconsin dairy farms, a higher efficiency score was evident for dairy farms with milking frequency more than twice a day (the variable $M \_F R E Q$ ). Another farm practice that was significantly associated with TE score was having automatic takeoff milking units (the variable M_AUTOMATIC). Compared with their counterparts, dairy farms with automatic takeoff milking units had higher TE scores, by 0.05 points, on average. Moreover, results in Table 3 showed that large and small farms with automatic takeoff milking units were more efficient by 0.04 and 0.03 points, respectively.

During the past $25 \mathrm{yr}$, dairy farmers have witnessed substantial changes in the role of veterinarians and nutritionists working with the dairy cattle. Services of nutritionists and veterinarians are also important for production efficiency. Compared with their counterparts, dairy farms using regularly scheduled veterinary services (the variable $F_{-}$VETERIN) had increased TE scores, by 0.03 points, on average. However, the effect of veterinary services was significant for large $(>300$ cows) and medium-sized farms (200-299 cows): large and medium-sized dairy farms with regularly scheduled veterinary services had higher TE scores, by 0.06 and 0.05 points, respectively (Table 3 ). Along the same line, farms using nutritionists (the variable $F_{-}$NUTRITION) had higher TE scores. Results indicate that small farms using nutritionists were able to increase their TE by 0.04 points. Finally, different sources of pasture also matter. Dairy farms with purchased pasture had lower TE scores and the effect was more significant among the small dairy farms $(-0.058)$. 


\section{CONCLUSIONS}

Given the concerns on the effects of the MILC payments on dairy production in the United States, this paper addressed the issue by examining the effects of the MILC payments on TE of US dairy farms. In particular, we investigated whether MILC payments had differential effects on the efficiency of dairy farms of different sizes. A 2-stage approach that combined the data envelopment analysis method and the Tobit regression model was proposed. Using a large-scale sample of the dairy farms in the United States, our results indicated that MILC payments were positively associated with the TE of the dairy farms. By further defining small, medium, and large dairy farms based on different herd sizes, it was evident that the effects were heterogeneous among farms of different sizes. Significant effects of MILC were only evident among large farms. In contrast, no significant effect was found for medium-sized and small farms. The MILC payments were designed to provide revenue support, during periods of low prices, to small operations and to the regions where such farms dominate. Our findings suggest that large dairy farms have benefited the most from this program: higher MILC payments were associated with increased efficiency on those large farms. It is plausible that large dairy farms are investing money in dairy operations and initiating business practices that reduce costs. Operators may have discovered ways to more effectively manage much larger dairy farms in recent years, and the bulk of new large farm investments appears directed at those much larger dairy farms. In turn, those investments may place even greater cost pressures on smaller operations. Findings from this study provide some evidence that counters that of critics of the MILC program - that the program blocks market signals and encourages inefficient producers to continue in business without becoming more competitive.

\section{ACKNOWLEDGMENTS}

The authors acknowledge the helpful comments received from anonymous referees and the section editor. H. H. Chang's time on this paper was supported by the College of Bioresources and Agriculture at the National Taiwan University. A. K. Mishra's time on this project was supported by the USDA Cooperative State Research Education and Extension Service, Hatch project \# 0212495 and Louisiana State University Experiment Station project \# LAB 93872. The views expressed here are not necessarily those of the Economic Research Service or the US Department of Agriculture or the
College of Bioresource and Agriculture at the National Taiwan University.

\section{REFERENCES}

Abdulai, A., and H. Tietje. 2007. Estimating technical efficiency under unobserved heterogeneity with stochastic frontier models: Application to northern German dairy farms. Eur. Rev. Agric. Econ. 34:393-416.

Balcombe, K., I. Fraser, and J. H. Kim. 2006. Estimating technical efficiency of Australian dairy farms using alternative frontier methodologies. Appl. Econ. 38:2221-2236.

Bravo-Ureta, B., D. Solís, V. Moreira, J. Maripani, A. Thiam, and T. Rivas. 2007. Technical efficiency in farming: A meta-regression analysis. J. Prod. Anal. 27:57-72.

Cabrera, V. E., D. Solis, and J. del Corral. 2010. Determinants of technical efficiency among dairy farms in Wisconsin. J. Dairy Sci. 93:387-393.

Chite, R. M. 2007. Dairy policy issues. CRS report for Congress, Congressional Research Service, Washington, DC.

Coelli, T. J., D. S. Rao, C. J. O'Donnell, and G. E. Battee. 2005. An Introduction to Efficiency and Productivity Analysis. 2nd ed. Springer Science Inc., New York, NY.

D'Haese, M. D., S. Speelman, V. Alary, E. Tillard, and L. D'Haese. 2009. Efficiency in milk production on Reunion Island: Dealing with land scarcity. J. Dairy Sci. 92:3676-3683.

Eberle, P. R., C. R. Milliman, W. C. Peterson, and C. M. Rendleman. 2004. Promotional efforts vs. economic factors as drivers of producer's decision to expand or start a dairy. Proc. Am. Agric. Econ. Assoc. annual meeting, Denver, Colorado. http://ageconsearch. umn.edu/bitstream/20140/1/sp04eb01.pdf.

Fare, R., S. Grosskopf, and C. Lovell. 1994. Production Frontiers. Cambridge University Press, New York, NY.

Farrell, M. J. 1957. The measurement of productive efficiency. J. R. Stat. Soc. [Ser A] 120:253-290.

Greene, W. 2008. Econometric Analysis. 6th ed. Pearson Education Inc., Upper Saddle River, NJ.

Herndon, C., B. Davis, and G. Parkhurst. 2005. Does the MILC program affect milk supply response across regions for the U.S.? Proc. Am. Agric. Econ. Assoc. annual meeting, Providence, Rhode Island. http://ageconsearch.umn.edu/bitstream/19438/1/sp05he06. pdf.

Huffman, W. E. 1981. Black-white human capital differences: Impact on agricultural productivity in the U.S. south. Am. Econ. Rev. 71:94-107.

Jesse, E., R. Cropp, and B. W. Gould. 2008. Dairy Subtitle: Food, Conservation, and Energy Act of 2008. Market and Policy Briefing Paper. Department of Agricultural and Applied Economics, University of Wisconsin-Madison Cooperative Extension, Madison.

Kompas, T., and T. N. Che. 2006. Technology choice and efficiency on Australian dairy farms. Aust. J. Agric. Resour. Econ. 50:65-83.

Lawson, L. G., J. Bruun, T. Coelli, and M. Lund. 2004. Relationships of efficiency to reproductive disorders in Danish milk production: A stochastic production analysis. J. Dairy Sci. 87:212-224.

Mishra, A. K., H. S. El-Osta, M. J. Morehart, J. D. Johnson, and J. W. Hopkins. 2002. Income, Wealth, and the Economic Well-Being of Farm Households. AER-812. USDA, Economic Research Service, Washington, DC.

Nehring, R., J. Gillespie, C. Sandretto, and C. Hallahan. 2009. Small U.S. dairy farms: Can they compete? Agric. Econ. 40:817-825.

Tauer, L. W., and A. K. Mishra. 2006. Dairy farm cost efficiency. J. Dairy Sci. 89:4937-4943.

Thiam, A., B. E. Bravo-Ureta, and T. E. Rivas. 2001. Technical efficiency in developing country agriculture: A meta-analysis. Agric. Econ. 25:235-243.

USDA Economic Research Service. 2005. Agricultural Resource Management Survey. USDA, Washington, DC. 